\title{
Statins in Acute Coronary Syndromes
}

\author{
Alexandre Russo Sposito, Gentil Barreira de Aguiar Filho, Amanda Rezende Aarão, Francisco Thiago Tomaz de \\ Sousa, Marcelo Chiara Bertolami \\ Instituto Dante Pazzanese de Cardiologia da Secretaria de Estado da Saúde de São Paulo, SP - Brazil
}

\begin{abstract}
Statins are the main resource available to reduce LDL-cholesterol levels. Their continuous use decreases cardiovascular morbidity and mortality due to atherosclerosis. The administration of these medications demonstrated to be effective in primary and secondary prevention clinical trials in low and high risk patients. Specialists believe that a possible benefit of hypolipidemic therapy in preventing complications of atherosclerotic diseases is in the reduction of deposition of atherogenic lipoproteins in vulnerable areas of the vasculature.

Experimental studies with statins have shown an enormous variety of other effects that could extend the clinical benefit beyond the lipid profile modification itself. Statinbased therapies benefit other important components of the atherothrombotic process: inflammation, oxidation, coagulation, fibrinolysis, endothelial function, vasoreactivity and platelet function. The demonstration of the effects that do not depend on cholesterol lowering or the pleiotropic effects of statins provides the theoretical basis for their potential role as adjunctive therapy in acute coronary syndromes.

Retrospective analyses of a variety of studies indicate the potential benefit of statins during acute coronary events. Recent clinical studies have addressed this important issue in prospective controlled trials showing strong evidence for the administration of statins as adjunctive therapy in acute coronary syndromes.
\end{abstract}

\section{Introduction}

Atherosclerosis, the main substrate of cardiovascular diseases, is a consequence of the arterial wall response to multiple aggressors, consisting of items of proliferation, deposition of lipids and inflammation characterized by the presence of macrophages, monocytes, lymphocytes and other cells. Almost all myocardial infarctions result from coronary atherosclerosis, often with superimposed thrombosis. Thus, during the natural evolution of atherosclerotic plaques,

\section{Keywords}

Hydroxymethylglutaryl-CoA reductase inhibitors; lipids; acute coronary syndrome; atherosclerosis; genetic pleiotropy/ drug effects.

Mailing address: Marcelo Chiara Bertolami •

Av. Sabiá, 667/141 - 04515-001 - Moema - São Paulo, SP - Brazil

E-mail: mchiara@cardiol.br, bertolami@uol.com.br

Manuscript received September 18, 2010; revised manuscript received

September 18, 2010; accepted on March 24, 2011. especially those laden with lipids, an abrupt and catastrophic transition characterized by plaque rupture may occur.

After this rupture, there is exposure to substances that promote platelet activation and aggregation, thrombin generation and ultimately thrombus formation. The thrombus stops blood flow and leads to an imbalance between oxygen supply and demand, and if this imbalance is severe and persistent, there will be myocardial necrosis. Pioneering studies that evaluated the angiographic features in acute myocardial infarction (AMI) showed that most acute coronary syndromes (ACS) (approximately 90\%) are secondary to vascular occlusion by a thrombus, which occurs on a previous culprit lesion ${ }^{1}$.

The concept of vulnerable plaque was subsequently developed to explain the pathophysiology of unstable angina and $\mathrm{AMI}^{2}$.

Pathological anatomy studies have shown multiple characteristics that make a previously stable atherosclerotic plaque into an occlusive vascular thrombus. The main pathological characteristics of the vulnerable plaque include: thin fibrous cap with reduced tensile strength, lipid content exceeding $40 \%$ of plaque volume, decreased intraplaque calcium, eccentric growth (positive remodeling) and inflammatory cell infiltration ${ }^{3}$.

When plaque rupture occurs, thrombogenic substances from inside are exposed to the circulating blood and the light of the coronary artery can become blocked by a combination of aggregated platelets, fibrin and erythrocytes.

An adequate collateral network that prevents necrosis can result in clinically silent episodes of coronary artery occlusion. Plaque rupture is currently considered the common pathophysiological substrate for ACS.

Characteristically, occlusive thrombus leads to a large area of necrosis involving the entire or almost the entire ventricular wall thickness in myocardial bed supplied by the affected coronary artery and typically produces ST-segment elevation in ECG.

The long-term use of cholesterol-lowering drugs, mostly statins, although they are not considered anti-ischemic agents, has demonstrated a reduction in mortality due to recurrent infarction and rehospitalization in survivors with SCA. Probably, the basic mechanisms for such clinical benefit involve improved vasomotor function, reduced plaque inflammation and reduction of prothrombotic factors. These changes in molecular biology affect not only the culprit lesion but also other plaques distributed across coronary arteries.

The initiation of statin therapy during hospitalization has been shown to increase adherence to these medications, thus reducing the risk of death and cardiovascular events in the long term. 
Synthesis of cholesterol in acute myocardial infarction

$\mathrm{AMI}$ is associated with profound changes in lipid profile. The mechanism of these changes is unclear, and both increased and decreased regulation of the cholesterol biosynthesis could be a consequence of AMI.

Pfohl et al ${ }^{4}$ observed changes in lipid profile of patients with $\mathrm{AMI}$ and symptom onset within 12 hours, collecting samples at hospital admission in the first, second and $10^{\text {th }}$ day after admission. On day 1 , there was a decrease in total cholesterol of $14.1 \%(p=0.01)$, LDL-cholesterol by $14.4 \%(p=0.03)$, rates of HDL cholesterol by $9.3 \%$ (NS) and triglycerides by $19.5 \%$ (NS). Apolipoprotein B100 was reduced by 18.3\% ( $p$ $=0.008$ ) and apolipoprotein A1 by $12.3 \%$ (NS). Unlike what was expected, cholesterol synthesis assessed by measuring its precursor, the serum lathosterol, presented a significant increase. The ratio of serum lathosterol/cholesterol increased by $23.1 \%$ after the first day to $28.7 \%$ after the second day ( $p$ $=0.05$ ). After 10 days, all variables except the apolipoproteins had almost returned to baseline values.

The authors concluded that the changes in lipid profile after AMI are associated with a marked increase in cholesterol biosynthesis. They suggested that this increase is explained by the body's response to greater need for cholesterol in myocardial tissue repair. Given this possibility, they raised the following question: the reduction of cholesterol induced by treatment during ACS could bring more losses than benefits.

\section{Possible mechanisms of the benefits provided by statins in ACS}

The use of statins is based on the reduction of blood levels of LDL-cholesterol (LDL-C), as these represent an important independent risk factor for CAD. Several studies have demonstrated the effectiveness of statins to reduce LDL-C and risk of clinical events in patients with stable CAD.

Currently, new benefits of statin, perhaps not dependent on the reduction of LDL-C, are being studied. These effects not dependent on the reduction of LDL-C are called pleiotropic.

Some of the possible effects of statins, which may participate in the benefits that they represent for the ACS, are listed in Table $1^{5}$.

It is still under discussion whether the pleiotropic effects result from actions dependent on cholesterol lowering, actions independent of cholesterol reduction, but dependent on inhibition of HMG-CoA reductase, actions independent of HMG-CoA reductase inhibition or a combination of these separate actions ${ }^{6}$.

\section{Evidence of benefits of statins in ACS}

\section{Observational studies}

The study The Platelet Receptor Inhibition in Ischemic Syndrome Management (PRISM) ${ }^{7}$ was designed to test the role of platelets in ACS, as well as the potential benefit of statins on the rate of cardiac events in 1,616 patients in a retrospective analysis. The administration of statins was associated with a reduction in the rate of events (odds ratio [OR] 0.49), which was statistically significant. However, if statin
Table 1 - Pleiotropic effects of statins possibly involved in the benefits that these drugs offer during the $\mathrm{ACS}^{5}$

\begin{tabular}{l}
\hline Decreased \\
\hline degree of inflammation (reduction of macrophages) \\
\hline oxidative stress \\
\hline activity of the metalloproteinase matrix (MMP) in atherosclerotic plaques \\
\hline $\begin{array}{l}\text { large variety of proinflammatory mediators, including, for example, interleukin-1 } \\
\text { (IL-1), interferon gamma, interleukin-6 (IL-6) and soluble CD40 ligand }\end{array}$ \\
\hline circulating rates of C-reactive protein (CRP) \\
\hline levels of plasminogen activator inhibitor-1 (PAl-1) \\
\hline $\begin{array}{l}\text { levels of Tissue Factor (TF), limiting the onset and progression of an } \\
\text { intracoronary thrombus }\end{array}$ \\
\hline Increased \\
\hline collagen deposition \\
\hline production of nitric oxide (NO), improving endothelial function \\
\hline $\begin{array}{l}\text { number of circulating endothelial progenitor cells and inhibition of apoptosis of } \\
\text { endothelial cells, leading to improved repair of injured endothelium }\end{array}$ \\
\hline
\end{tabular}

therapy was discontinued during hospitalization there would be a significantly increased risk of developing cardiovascular events (OR 2.93).

Although in a retrospective study the PRISM analysis supports the role of statins in ACS and suggests worsening of clinical course with its discontinuation at the time of admission, which can be explained by an increase of factors related to the risk of intracoronary thrombosis and vasospasm. However, the results are controversial and have not been verified in retrospective analyses of other studies.

\section{Records}

The Global Registry of Acute Coronary Events (GRACE) ${ }^{8}$ involved 20,000 patients and compared those who had not started statins during hospitalization with those who discontinued these medications and those who continued using during this period. The latter had significantly lower combined risk of myocardial infarction, CVA or death (OR $0.66 ; 95 \% \mathrm{Cl} 0.56$ to 0.77 ). Furthermore, early use of statins at hospital admission was also beneficial (OR 0.87; CI95\%, 0.78-0.97). However, patients who discontinued statin therapy upon admission had a similar risk as those who have never received statins (OR 1.02; 95\% $\mathrm{Cl}, 0.74$ to 1.41 ).

Likewise, the National Registry of Myocardial Infarction ${ }^{9,10}$ analyzed the role of statin therapy or discontinuation in 300,000 patients admitted for acute myocardial infarction without STsegment elevation (NSTEMI). Patients who never received statins before or after hospitalization, totaled 54,635 and served as a comparison group. Patients who continued statin therapy and those who started during hospitalization had a lower risk of death (OR $0.46 ; 95 \% \mathrm{Cl}, 0.42$ to 0.50 and OR $0.42,95 \%, 0.38$ to 0.45 , respectively). It was also noted that discontinuation of statins ( $n=4,870$ ) was associated with increased risk of events, including death, heart failure, ventricular arrhythmia and cardiogenic shock (OR 1.25; 95\% Cl, 1.15 to 1.36).

The data in this record demonstrate the benefit of statins when started immediately after an episode of ACS, 


\section{Review Article}

strengthening the role of pleiotropic mechanism, rather than the effect of lowering LDL-C in the slow progression of plaque and cholesterol deposits ${ }^{11}$.

Likewise, the analysis of the Swedish registry (Riks-HIA), included studies of 19,599 patients admitted to a cardiac intensive care unit with diagnosis of $\mathrm{AMI}$, and $28 \%$ used statins before hospital discharge. After one year of follow-up, the unadjusted mortality rate was $4 \%$ compared with $9 \%$ of patients not receiving statins before hospital discharge. Regression analysis adjusted for factors that could confuse the unfavorable outcomes showed that early statin was associated with a reduction of $25 \%$ relative risk of death within one year $(95 \% \mathrm{Cl} / 0.63 \text { to } 0.89 \% / \mathrm{p}=0.001)^{12}$.

\section{Controlled studies}

\section{Early studies}

A strong argument against the start of statin therapy during hospitalization was based on the assumption that there could be greater risks of adverse effects for patients hospitalized for acute coronary event than those with stable coronary artery disease. There was therefore a need to assess whether statin therapy initiated during the acute phase, soon after the ischemic event, would be well tolerated, i.e., no higher incidence of adverse effects in acute patients compared with patients with stable coronary artery disease. The studies PAIS (Pravastatin in Acute Ischaemic Syndromes) ${ }^{13}$ and LAMIL (Lipids and Apolipoproteins after Acute Myocardial Infarction) ${ }^{14}$ provided this response, demonstrating that the use of a statin, in this case, pravastatin, after hospitalization for ACS, was well tolerated and has produced a significant reduction of total cholesterol and LDL-C, besides increased HDL-C.

The study RECIFE (Reduction of Cholesterol in Ischemia and Function of the Endothelium $)^{15}$ was a randomized, double blind, prospective study involving 60 patients, which compared placebo versus $40 \mathrm{mg} /$ day of pravastatin for 6 weeks. The primary objective was to evaluate the effect of rapid cholesterol reduction on vascular endothelial reactivity measured by noninvasive measurement of high resolution ultrasound, dilation and brachial artery flow after acute myocardial infarction or unstable angina. Secondary objectives included the evaluation of hemodynamic factors, platelet activity and concentrations of endothelin-1. With pravastatin, but not with placebo, there was reduction in total cholesterol and LDL-c in $23 \%(p=0.05)$ and $33 \%(p=0.01)$, respectively.

Regarding hemodynamic parameters, endothelindependent dilation, as measured by the percentage of flow-dependent dilation was similar in both groups at randomization, with no significant variation in the placebo group after 6 weeks. However, in the group treated with pravastatin, there was increased flow of $42 \%$ compared to the values of acceptance, $p=0.02$. It was noted, however, that this effect was not related to the drop in rates of cholesterol. The response of endothelin-independent dilation was similar in both groups. This result was particularly important in the early phase of ACS at high risk of recurrent cardiovascular events.

It was postulated therefore that improvement of endothelial function would be the mechanism by which the reduction of cholesterol would induce stabilization of atherosclerotic plaques leading to a decrease of AMIs and deaths from coronary heart diseases.

The clinical trial L-CAD (Lipid-Coronary Artery Disease Study) ${ }^{16}$, also testing the pravastatin, established correlation between ACS and analysis of the coronary angiogram. In this study, 126 patients with AMI or those who underwent coronary angioplasty for unstable angina with total cholesterol between 200 and $400 \mathrm{mg} / \mathrm{dl}$ and LDL-c between 130 and $300 \mathrm{mg} / \mathrm{dl}$ were randomized for immediate use (6 days after the event on average) of intensive cholesterol-lowering or lipid-lowering treatment.

In the intensive treatment group, pravastatin was used alone or in combination with cholestyramine and/or nicotinic acid for reduction of LDL-C at rates below $130 \mathrm{mg} / \mathrm{dl}$. Patients randomized to the group of intensive cholesterol lowering showed progression of stenosis assessed by quantitative coronary angiography significantly lower in the intensive treatment group compared with usual treatment, in which disease progression was greater. Moreover, after 24 months of follow up, the intensive reduction group had a significantly smaller reduction in clinical events (23\% vs $52 \%)$ than the control group (95\% Cl: 0.13-0.60 / p < 0.005).

\section{Studies that assessed statins in moderate doses}

Two studies, Fluvastatin On Risk Diminishment after Acute Myocardial Infarction (FLORIDA) $)^{17}$ and Pravastatin in Acute Coronary Treatment (PACT) ${ }^{18}$ have tested the use of moderate doses of statins with disappointing results in relation to the outcomes of death, myocardial infarction and recurrent angina despite significant reduction in serum levels of LDL cholesterol.

The FLORIDA ${ }^{17}$ study involved 540 patients randomized to receive either $80 \mathrm{mg} /$ day of fluvastatin or placebo within 15 days from the acute event, with follow up of 12 months. At the end of the study, LDL-c was reduced by $21 \%$ compared with an increase of $9 \%$ in the placebo group $(p<0.001)$. Despite the difference in rates of LDL cholesterol, there was no difference in the composite endpoint of AMI, death, recurrent ACS or ischemia on $24 \mathrm{~h}$ ECG (33\% in the fluvastatin group and $36 \%$ in the placebo group; $p=0.34$ ). This study, however, has been criticized by the small number of patients included and the delay in starting treatment.

The $P A C T{ }^{18}$ study randomized 3,408 patients to receive 20 to $40 \mathrm{mg} /$ day of pravastatin or placebo, with 30-day follow-up.

There was no significant reduction in the composite endpoint of death, $\mathrm{AMI}$ and readmission for angina (HR 0.94; $p=0.48)$, although there was a tendency in favor of the statin group.

\section{Studies that assessed statins in high doses}

Finally, three large studies have investigated the intensive therapy with statins immediately after ACS.

A to $Z$ Trial $^{19}$ was an international, randomized, doubleblind study that compared intensive therapy by statins started early with less intensive therapy and started late in patients with ACS. Patients $(n=2,265)$ received $40 \mathrm{mg} /$ day of simvastatin for a month and then $80 \mathrm{mg} /$ day compared with the control group that received placebo for 4 months and then 
simvastatin $20 \mathrm{mg} /$ day $(\mathrm{n}=2,232)$. The study involved 4,497 patients and had follow-up period between 6 and 24 months. The group receiving statins from the outset, the rates of LDL-C after one month and 8 months of treatment were respectively $68 \mathrm{mg} / \mathrm{dl}$ and $63 \mathrm{mg} / \mathrm{dl}$, while in the placebo group these rates were $122 \mathrm{mg} / \mathrm{dl}$ and $77 \mathrm{mg} / \mathrm{dl}$, respectively.

As for the primary composite endpoint of recurrent angina, nonfatal myocardial infarction, CVA and cardiovascular death, there was no statistically significant benefit during the first four months. However, after 4 months, there was a reduction in the primary outcome in the group that used statin intensely (OR $0.75 ; 95 \% \mathrm{Cl} 0.60$ to $0.95, \mathrm{p}=0.02$ ), although there was increased number of adverse effects such as myopathy (increased by 10 times the upper limit of creatine phosphokinase with symptoms) in the intensive therapy group of $0.4 \%$, compared to less than $0.001 \%$ in the group receiving placebo $(p=0.2)$.

The study Myocardial Ischemia Reduction with Aggressive Cholesterol Lowering (MIRACL) ${ }^{20}$ was the largest study designed to test the hypothesis that early use of statins in ACS would provide benefits.

It was a double-blind study conducted between May 1997 and September 1999, with 16-week follow-up in 122 centers worldwide. It randomized 3,086 patients older than 18 years with ACS without ST segment for treatment with high dose of atorvastatin (80 mg/day) or placebo, initiated between 24 and 96 hours after ACS, to evaluate the reduction in risk of death and nonfatal ischemic events. The primary composite endpoint defined as total mortality, fatal and nonfatal AMI, cardiac arrest and recurrent ischemia requiring hospitalization, occurred in 228 patients $(14.8 \%)$ in the atorvastatin group compared with 269 patients (17.4\%) in the placebo group, a noticeable decrease, but to the limit of statistical significance (OR 0.84; $p=0.048)$.

Additionally, analysis of the components of the primary outcome showed no statistically significant reductions in overall mortality, nonfatal myocardial infarction and cardiac arrest. Most clinical benefits occurred as a result of the reduction of symptomatic ischemia requiring hospitalization. We have noticed, however, in the active treatment group, a reduction in average LDL-c of $42 \%$ (124 to $72 \mathrm{mg} / \mathrm{dl}$ ) and a significant decrease in the rate of CVA (OR 0.49; $p=0.04$ ).

The Pravastatin or Atorvastatin Evaluation and Infection Therapy-Trombolysis in Myocardial Infarctation 22 (PROVE IT-TIMI 22) ${ }^{21}$ was a study that compared moderate regime of treatment with $40 \mathrm{mg} /$ day of pravastatin against intense regime of $80 \mathrm{mg} /$ day of atorvastatin, with the hypothesis that pravastatin was not inferior to atorvastatin, despite the lower power.

The sponsors of the study were betting on the pleiotropic effects of pravastatin.

The study randomized 4,162 patients admitted with ACS, who were followed up for 24 months. Higher reduction in rates of LDL-C in the intensive branch of treatment with atorvastatin compared with the pravastatin group (62 versus $95 \mathrm{mg} / \mathrm{dl})$, starting from similar basal rates in both groups. The primary composite endpoint of unstable angina, coronary artery bypass grafting after 30 days, myocardial infarction, CVA and death was clearly reduced in the intensive treatment group over the moderate treatment group (OR 0.84; $p=0.005$ ).

Further analyses revealed that the clinical benefits were apparent from the $15^{\text {th }}$ day, reaching statistical significance after 30 days. Possibly the greatest reductions in LDL-C observed with intensive treatment with atorvastatin were also accompanied by the highest power on the pleiotropic effects ${ }^{22}$.

Another study that compared intensive therapy versus moderate therapy with statins after an ACS was the Ideal Trial ${ }^{23}$, which randomized 8,888 patients into two groups.

One group received $80 \mathrm{mg} /$ day of atorvastatin, while the other received simvastatin at a dose of $20 \mathrm{mg} /$ day. The primary objective of this study was to compare in the two groups the prevalence of coronary events, characterized by death, hospitalization for nonfatal myocardial infarction or cardiac resuscitation. Regarding the primary outcome, the group receiving atorvastatin showed $9.3 \%$ of events compared to $10.4 \%$ in the group receiving simvastatin $(p=0.07)$. Although no statistical difference was found, the group that took atorvastatin had a lower rate of nonfatal myocardial infarctions.

The main data from these studies are summarized in Table 2.

\section{Perspective}

Relationship between HDL-cholesterol and risk of acute coronary syndrome

In several studies, low levels of HDL-c are associated with increased risk of ACS. The inverse relationship between rates of HDL-C and increased risk of events is also observed in patients with manifested coronary heart disease. The MIRACL study analyzed in 3,086 patients the relationship between lipoprotein values between one and four days of acute coronary event and after 4 months compared with the number of cardiovascular events and noted that the increase of $1.0 \mathrm{mg} / \mathrm{dl}$ in $\mathrm{HDL}-\mathrm{c}$ related to a reduction of $1.4 \%$ of events after 4 months ${ }^{24}$.

This raises the question of whether pharmacological interventions aimed at increasing HDL-c could early reduce the risk after ACS.

\section{Ongoing studies}

The Improved Reduction of Outcomes: Vytorin Efficacy International Trial (IMPROVE-IT) ${ }^{25}$, a randomized, active control, double-blind study, will examine 18,000 patients with ACS who were randomized for $40 \mathrm{mg} /$ day of simvastatin or a combination of ezetimibe $10 \mathrm{mg}$ daily and simvastatin at the same dose. The dose of statin may be increased to $80 \mathrm{mg} /$ day according to the need in both branches. The primary objective is to reduce the risk of event composed of cardiovascular death, major coronary events and CVA. The end of this study is planned for $2013^{26}$.

The 24-HOUR TRIAL is a proposal for a Brazilian study that is being evaluated by the Brazilian Society of Cardiology. The primary goal will be to determine whether the therapeutic strategy of acute myocardial infarction with ST-segment elevation or NSTEMI (TIMI $\geq 4$ ), during hospitalization, 


\section{Review Article}

Table 2 - Controlled studies

\begin{tabular}{|c|c|c|c|c|}
\hline \multicolumn{5}{|c|}{ Controlled studies } \\
\hline \multicolumn{5}{|c|}{ Early studies } \\
\hline Study & $\mathrm{n}$ & Therapy & Duration & Results \\
\hline RECIFE & 60 pat. post-AMI or UA & Prava $40 \times \mathrm{P}$ & 6 weeks & Improved endothelial function \\
\hline L-CAD & 126 pat. post-AMI or UA & $\begin{array}{l}\text { Prava }+ \text { cholest and/or niacin } \\
\text { X usual therapy }\end{array}$ & 24 months & $\begin{array}{l}\text { Smaller progression of plaque by cine and fewer } \mathrm{CV} \\
\text { events in the intensive treatment group }\end{array}$ \\
\hline \multicolumn{5}{|c|}{ Statins at moderate doses } \\
\hline FLORIDA & 540 pat. post ACS & Fluva $80 \mathrm{XP}$ & 12 months & $\begin{array}{l}\text { No differences composite endpoint of AMl, death, } \\
\text { recurrent ACS or ischemia in 24-hour Holter }\end{array}$ \\
\hline РАCT & 3.408 pat. post ACS & Prava 20 to $40 \mathrm{XP}$ & 30 days & $\begin{array}{l}\text { No reduction in the composite endpoint of death, AMI } \\
\text { and readmission for angina }\end{array}$ \\
\hline \multicolumn{5}{|c|}{ Statins at high doses } \\
\hline A to $Z$ & 4,497 pat. post ACS & $\begin{array}{l}\text { 2.265-simva } 40 \text { (one month) } \\
\text { and then } 80 \\
\text { P-2232 (4 months) and then } \\
\text { simvastatin } 20\end{array}$ & $\begin{array}{l}6 \text { to } 24 \\
\text { months }\end{array}$ & $\begin{array}{l}\text { No difference combined primary outcome of RA, } \\
\text { nonfatal AMI, CV death and CVA in the first four } \\
\text { months. After four months - reduced primary outcome in } \\
\text { intensive treatment group. }\end{array}$ \\
\hline MIRACL & $\begin{array}{l}\text { 3,086 pat. with ACS without } \\
\text { ST elevation }\end{array}$ & Atorva $80 \mathrm{XP}$ & 16 weeks & $\begin{array}{l}\text { Reduced primary composite endpoint (TM, fatal and } \\
\text { nonfatal AMI, CA and RA requiring hospitalization) }\end{array}$ \\
\hline PROVE IT-TIMI 22 & 4,162 pat. with ACS & Atorva $80 \mathrm{X}$ Prava 40 & 24 months & $\begin{array}{l}\text { Reduced primary composite endpoint of UA, CABG, } \\
\qquad \mathrm{AMI}, \mathrm{CVA} \text { and death }\end{array}$ \\
\hline IDEAL & 8,888 pat. post ACS & ATORVA $80 \mathrm{X}$ simvastatin 20 & & $\begin{array}{l}\text { No differences in the primary objective (death, } \\
\text { hospitalization for nonfatal AMl or CABG) }\end{array}$ \\
\hline \multicolumn{5}{|c|}{ 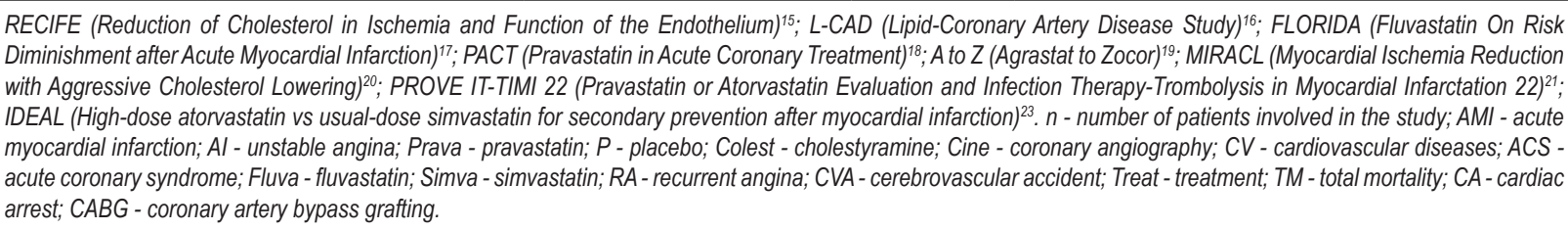 } \\
\hline
\end{tabular}

including the use of potent statin alone or associated with incretin (associated with insulin if necessary) in the first 24 hours, can reduce mortality and major cardiovascular events (CV death, cardiogenic shock, fibrillation/VT, CVA, heart failure) during the first three months, compared to the use of the same statin, after $24 \mathrm{~h}$, alone or combined with insulin therapy (if necessary) without the use of incretin. This study may influence future directions in myocardial infarction. It will be the first prospective study to test the isolated or combined effects of complementary actions (pleiotropic) of statins and incretins.

\section{Conclusions and recommendations}

ACS, including unstable angina and acute myocardial infarction with or without ST-segment elevation in the last decade, suffered a great revolution from the therapeutic point of view.

However, despite the great technological and pharmacological progress, patients still have a high risk of recurrent coronary events in the short term, when compared with those with stable coronary artery disease.

In this scenario, the regular use of statins has proven to reduce the risk of coronary events in high risk patients, including diabetic patients with chronic CAD and in ACS.
There is no consensus on the use of statins in ACS, so the $4^{\text {th }}$ Brazilian Guidelines on Dyslipidemia and Prevention of Atherosclerosis of Brazilian Society of Cardiology ${ }^{27}$ make the following considerations on the use of statins in ACS: in addition to increasing adherence to treatment, scientific evidence show benefit in the early use of statins in this population.

Therefore, the use of statins is indicated for individuals with acute coronary syndromes, with a therapeutic target of LDL-C $<70 \mathrm{mg} / \mathrm{dl}$.

The $4^{\text {th }}$ Guideline of the Brazilian Society of Cardiology on the Treatment of Acute Myocardial Infarction with ST-segment Elevation ${ }^{28}$ recommends that measurement of LDL-cholesterol should occur preferably at admission or 24 hours after admission, and should be used to guide the introduction of lipid-lowering therapy. According to this Guideline, patients with LDL-cholesterol $\geq 100 \mathrm{mg} /$ $\mathrm{dl}$ should start lowering therapy in the emergency room. In patients with LDL-cholesterol $\geq 100 \mathrm{mg} / \mathrm{dl}$ under treatment, the dose of medication should be increased and, if necessary, a combination of drugs should be used. In patients with LDL-cholesterol levels between 70-100 mg/dl, it is reasonable to reduce LDL cholesterol to lower levels.

In daily practice, there is a number of situations involving statin therapy in ACS that are not addressed by these Guidelines. Considering this, based on the information 
discussed in this review, the authors propose the following conclusions and recommendations on the use of statins in ACS:

1. The tolerability of statins in ACS is good and similar to that observed in chronic patients;

2. Every patient with SCA must take potent statin at a high dose as soon as possible, unless there are formal contraindications such as uncontrolled hypothyroidism or acute liver disease.

3. The rates of LDL-C decrease significantly after the first 24 hours of onset of acute event and take about three months to return to previous levels. Given this, it is recommended to collect material for determination of lipid profile as soon as the patient gets to the emergency room, where blood is collected for other routine determinations of the acute phase;

4. If the patient is already using lipid-lowering medication when hospitalized for ACS, the medication should be kept, since the increased rate of LDL-c can produce worsening of endothelial dysfunction and inflammation, with consequent increase in morbidity and mortality. If the medication previously used has a lower power and/or a low dose was taken, it is recommend to replace it with a potent statin at a high dose (despite lacking evidence to support this indication);

5. It is discussed whether patients who already have LDL-C measured earlier than 24 hours of hospitalization below $70 \mathrm{mg} / \mathrm{dl}$ (on statins or not) will benefit from treatment or its intensification, but in general it is recommended;

6. Always include statins among hospital discharge drugs in order to increase adherence in the short and long term thereby reducing the incidence of cardiovascular events among those patients who are at high risk for new events;

7. Seek evidence that the rates of LDL-C are appropriate for secondary prevention (below $70 \mathrm{mg} / \mathrm{dl}$ ) before discharge. If not, statins may be associated with drugs that assist in reducing LDL-C, such as ezetimibe, cholestyramine or niacin. Meanwhile, there is evidence that these associations will be able to bring benefits in reducing cardiovascular events.

8. Three months after discharge from the acute event, request determination of lipid profile to adapt the treatment if necessary, to achieve the target of LDL-C for secondary prevention $(<70 \mathrm{mg} / \mathrm{dl})$. If the LDL-c is above that rate, the suggestion is to change for a more powerful statin or increase the dose, if possible and if necessary, and associate drugs (ezetimibe, cholestyramine or nicotinic acid). If the LDL-C is well below target $(<70 \mathrm{mg} / \mathrm{dl})$, although there is no consensus, reducing the dose to use the smallest dose needed to achieve the target is suggested. In general, dose reduction when LDL-c is smaller than $50 \mathrm{mg} / \mathrm{dl}^{29}$ has been suggested;

9. Results of studies that may show that the earlier the treatment is started after the diagnosis of SCA the greater the benefit are expected. Likewise, whether the LDL-c targets in secondary prevention should be even lower than those currently recommended;

10. We wait for data that could reveal whether the adjunctive treatment targeting $\mathrm{HDL}-\mathrm{c}$ is able to complement early and intensive therapy with statins, further reducing the risk after an episode of ACS.

\section{Potential Conflict of Interest}

No potential conflict of interest relevant to this article was reported.

\section{Sources of Funding}

There were no external funding sources for this study.

\section{Study Association}

This study is not associated with any post-graduation program.

\section{References}

1. Ellis S, Alderman E, Cain K, Fisher L, Sanders W, Bourassa M. Prediction of risk of anterior myocardial infarction by lesion severity and measurement method of stenoses in the left anterior descending coronary distribution: a CASS Registry Study. J Am Coll Cardiol. 1988;11(5):908-16.

2. Libby P. Current concepts of the pathogenesis of the acute coronary syndromes. Circulation. 2001;104(3):365-72.

3. Finn AV, Nakano M, Narula J, Kolodgie FD, Virmani R. Concept of vulnerable/ unstable plaque. Arterioscler Thromb Vasc Biol. 2010;30(7):1282-92.

4. Pfohl M, Schreiber I, Liebich HM, Haring HU, Hoffmeister HM. Upregulation of cholesterol synthesis after acute myocardial infarction--is cholesterol a positive acute phase reactant? Atherosclerosis. 1999;142(2):389-93.
5. LiaoJK. Effects of statins on 3-hydroxy-3-methylglutaryl coenzyme a reductase inhibition beyond low-density lipoprotein cholesterol. Am J Cardiol. 2005;96(5A):24F-33F.

6. Sposito AC, Chapman MJ. Statin therapy in acute coronary syndromes: mechanistic insight into clinical benefit. Arterioscler Thromb Vasc Biol. 2002;22(10):1524-34

7. Heeschen C, Hamm CW, Laufs U, Snapinn S, Bohm M, White HD. Withdrawal of statins increases event rates in patients with acute coronary syndromes. Circulation. 2002;105(12):1446-52.

8. Spencer FA, Allegrone J, Goldberg RJ, Gore JM, Fox KA, Granger CB, et al Association of statin therapy with outcomes of acute coronary syndromes: the GRACE study. Ann Intern Med. 2004;140(11):857-66. 


\section{Review Article}

9. Spencer FA, Fonarow GC, Frederick PD, Wright RS, Every N, Goldberg RJ, et al. Early withdrawal of statin therapy in patients with non-ST-segment elevation myocardial infarction: national registry of myocardial infarction. Arch Intern Med. 2004;164(19):2162-8.

10. Fonarow GC, Wright RS, Spencer FA, Fredrick PD, Dong W, Every N, et al. Effect of statin use within the first 24 hours of admission for acute myocardial infarction on early morbidity and mortality. Am J Cardiol. 2005;96(5):611-6.

11. Liew TV, Ray KK. Intensive statin therapy in acute coronary syndromes. Curr Atheroscler Rep. 2008;10(2):158-63.

12. Stenestrand $U$, Wallentin L. Early statin treatment following acute myocardial infarction and 1-year survival. JAMA. 2001;285(4):430-6.

13. Den Hartog FR, Van Kalmthout PM, Van Loenhout TT, Schaafsma HJ, Rila $\mathrm{H}$, Verheugt FW. Pravastatin in acute ischaemic syndromes: results of a randomised placebo-controlled trial. Int J Clin Pract. 2001;55(5):300-4

14. Kesteloot H, Claeys G, Blanckaert N, Lesaffre E. Time course of serum lipids and apolipoproteins after acute myocardial infarction: modification by pravastatin. Acta Cardiol. 1997;52(2):107-16.

15. Dupuis J, Tardif JC, Cernacek P, Theroux P. Cholesterol reduction rapidly improves endothelial function after acute coronary syndromes. The RECIFE (reduction of cholesterol in ischemia and function of the endothelium) trial. Circulation. 1999;99(25):3227-33.

16. Arntz HR, Agrawal R, Wunderlich W, Schnitzer L, Stern R, Fischer F, et al. Beneficial effects of pravastatin (+/-colestyramine/niacin) initiated immediately after a coronary event (the randomized Lipid-Coronary Artery Disease [L-CAD] Study). Am J Cardiol. 2000;86(12):1293-8.

17. Liem AH, van Boven AJ, Veeger NJ, Withagen AJ, Robles de Medina RM, Tijssen JG, et al. Effect of fluvastatin on ischaemia following acute myocardial infarction: a randomized trial. Eur Heart J. 2002;23(24):1931-7.

18. Thompson PL, Meredith I, Amerena J, Campbell TJ, Sloman JG, Harris PJ. Effect of pravastatin compared with placebo initiated within 24 hours of onset of acute myocardial infarction or unstable angina: the Pravastatin in Acute Coronary Treatment (PACT) trial. Am Heart J. 2004;148(1):e2.

19. de Lemos JA, Blazing MA, WiviottSD, Lewis EF, Fox KA, White HD, et al. Early intensive vs a delayed conservative simvastatin strategy in patients with acute coronary syndromes: phase Z of the A to Z trial. JAMA. 2004;292(11):1307-16.
20. Schwartz GG, Olsson AG, Ezekowitz MD, Ganz P, Oliver MF, Waters D, et al. Effects of atorvastatin on early recurrent ischemic events in acute coronary syndromes: the MIRACL study: a randomized controlled trial. JAMA. 2001;285(13):1711-8.

21. Cannon CP, Braunwald E, McCabe CH, Rader DJ, Rouleau JL, Belder R, et al. Intensive versus moderate lipid lowering with statins after acute coronary syndromes. N Engl J Med. 2004;350(15):1495-504.

22. Ray KK, Cannon CP. Early time to benefit with intensive statin treatment: could it be the pleiotropic effects? Am J Cardiol. 2005;96(5A):54F-60F.

23. Pedersen TR, Faergeman O, Kastelein JJ, Olsson AG, Tikkanen MJ, Holme I, et al. High-dose atorvastatin vs usual-dose simvastatin for secondary prevention after myocardial infarction: the IDEAL study: a randomized controlled trial. JAMA. 2005;294(19):2437-45.

24. Olsson AG, Schwartz GG, Szarek M, Sasiela WJ, Ezekowitz MD, Ganz P, et al. High-density lipoprotein, but not low-density lipoprotein cholesterol levels influence short-term prognosis after acute coronary syndrome: results from the MIRACL trial. Eur Heart J. 2005;26(9):890-6.

25. Cannon CP, Giugliano RP, Blazing MA, Harrington RA, Peterson JL, Sisk CM, et al. Rationale and design of IMPROVE-IT (IMProved Reduction of Outcomes: Vytorin Efficacy International Trial): comparison of ezetimbe/simvastatin versus simvastatin monotherapy on cardiovascular outcomes in patients with acute coronary syndromes. Am Heart J. 2008;156(5):826-32.

26. Califf RM, Lokhnygina Y, Cannon CP, Stepanavage ME, McCabe CH, Musliner TA, et al. An update on the IMProved reduction of outcomes: Vytorin Efficacy International Trial (IMPROVE-IT) design. Am Heart J. 2010;159(5):705-9.

27. Sposito AC, Caramelli B, Fonseca FA, Bertolami MC, Afiune NA, Souza AD, et al. / Sociedade Brasileira de Cardiologia. IV Diretrizes brasileiras para dislipidemias e prevenção da aterosclerose. Arq Bras Cardiol. 2007;88 (supl 1):2-19.

28. Piegas LS, Timerman A, Feitosa G, Mattos LA, Nicolau JS, Rossi Neto JM, et al. / Sociedade Brasileira de Cardiologia. Diretriz sobre tratamento do infarto agudo do miocárdio com supradesnível do segmento ST. Arq Bras Cardiol. 2009;93(6 supl.2):e179-e264.

29. Forrester JS. Redefining normal low-density lipoprotein cholesterol: a strategy to unseat coronary disease as the nation's leading killer. J Am Coll Cardiol. 2010;56(8):630-6 